Eixo Temático: Biologia Aplicada

\title{
ET-09-011 \\ ABUNDÂNCIA DE ESPÉCIES NATIVAS E EXÓTICAS DE DROSOFILÍDEOS EM UM FRAGMENTO DE FLORESTA ATLÂNTICA E EM FLORESTAS PLANTADAS
}

Danubia Guimarães Silva ${ }^{1}$, Anna Claudia Aca Ferreira ${ }^{1}$, Tatiane França Melo ${ }^{1}$, Géssica Galdino da Silva², Claudia Rohde ${ }^{1}$, Martín Alejandro Montes³ ${ }^{3}$ Ana Cristina Lauer Garcia ${ }^{1}$

${ }^{1}$ Universidade Federal de Pernambuco - Centro Acadêmico de Vitória (UFPE/CAV) - Programa de Pós-Graduação em Saúde Humana e Meio Ambiente.

${ }^{2}$ Universidade Federal de Pernambuco - Centro Acadêmico de Vitória (UFPE/CAV) Graduanda do curso de Ciências Biológicas (Núcleo de Biologia).

${ }^{3}$ Universidade Federal Rural de Pernambuco (UFRPE/RECIFE) - Departamento de Biologia.

$$
\text { http://dx.doi.org/10.21472/congrebio2016.et-09-011 }
$$

\section{RESUMO}

As diversas atividades antropogênicas estão entre as principais responsáveis pela geração de territórios com componentes abióticos e bióticos muito distintos dos ambientes naturais. Estas alterações podem interferir na abundância das espécies nativas presentes no ambiente natural, ocasionando a extinção local de alguma destas espécies. As áreas de proteção ambiental estão entre uma das ferramentas que auxiliam na prevenção da biodiversidade, mas nem sempre a cobertura vegetal destes territórios é suficiente para a preservação das espécies. Dentro deste contexto, as áreas de plantação para a extração madeireira podem representar uma alternativa para a conservação da biodiversidade, podendo preservar mais espécies. Entre os biomas brasileiros, a Floresta Atlântica é o mais destruído pelas ações antrópicas, sendo, por isso, considerada uma das prioridades mundiais para a conservação da biodiversidade. Neste estudocomparamos a abundância de drosofilídeos exóticos e nativosda região Neotropical nas estações chuvosa e seca eem três áreas dentro do domínio da Floresta Atlântica no estado de Pernambuco: uma plantação de eucaliptos, uma plantação de bambus e um de fragmento de Floresta Atlântica, amboslocalizados no município de Moreno, Pernambuco. Em cada área foram realizadas seis amostragens de drosofilídeos, três no período de maior pluviosidade e três no período de maior estiagem. Foram coletados 28.666 indivíduos da família Drosophilidae nos ambientes investigados, deste total 49,39\% foram observados na área de Floresta nativa, 28,75\% na plantação de eucaliptos e 21,90\% na plantação de bambus. As espécies nativas foram significativamente mais abundantes em relação às exóticas na Floresta nativa e na plantação de bambus, na plantação de eucaliptos ocorreu o inverso, o que demostra que as plantações artificiais são heterogêneas em relação à abundância destes insetos. Durante a estação chuvosa às espécies nativas foram significativamente mais abundantes em relação às exóticas e um padrão inverso foi observado na estação seca. Os padrões de abundância aqui observados são discutidos de forma comparativa com outros estudos realizados com drosofilídeos. Nota-se que estes organismos são excelentes modelos para se estudar flutuações de abundância em relação a diferentes ambientes, bem comovariações sazonais.

Palavras-chave: Bambu; Eucalipto; Insetos.

\section{INTRODUÇÃO}

O desmatamento, os ciclos econômicos, a urbanização, a introdução de espécies exóticas e o plantio de espécies não nativas para extração madeireirasão responsáveis pela geração de territórios com componentes bióticos e abióticos muito distintos em comparação 
com os ambientes naturais. Estas mudanças no habitat, muitas vezes acarretadas por ações antropogênicas,podem interferir na abundância das espécies nativas presentes no ambiente natural, podendo levar a extinção local de algumas destas espécies (SUKOPP e WERNER, 1982).

Uma das medidas que auxiliam na prevenção da perda da biodiversidade são as áreas de proteção ambiental, porém nem sempre a cobertura vegetal destes territórios é suficiente para preservação das espécies (RODRIGUES et al., 2004). Partindo deste pressuposto, as áreas de plantações de árvores para extração madeireira podem representar uma importante alternativa para a conservação da biodiversidade, podendo ajudar a preservar mais espécies em comparação com usos alternativos e mais intensos de terras agrícolas (LINDENMAYER e FRANKLIN, 2002).

No Brasil, a Floresta Atlântica é um dos biomasmais destruídos pela ação humana. Esta éuma das regiões de maior diversidade biológica do planeta, abrigando muitas espécies endêmicas e sendo, por isso, considerada uma das maiores prioridades mundiais para conservação da biodiversidade biológica (CUNHA e GUEDES, 2013).

As moscas da Família Drosophilidae são excelentes modelos de estudo para a avaliação de diferentes ambientes na manutenção da biodiversidade, além de serem extremamente sensíveis às variações sazonais. Estes insetos são muito promissores em estudos ecológicos, pois sãomoscas pequenas, formadas por um grande número de espécies, facilmente capturadas na natureza e altamente sensíveis às variações de componentes abióticos (POWELL, 1997).

Diante desses aspectos, o presente trabalho comparou a abundância de drosofilídeos exóticos e nativosda região Neotropical na estação chuvosa e na estação seca em três áreas, sendo elas: uma de vegetação preservada, uma área de plantação de eucaliptos e outra de plantação de bambus dentro do domínio da Floresta Atlânticano Centro de Endemismo de Pernambuco.

\section{METODOLOGIA}

\section{Áreas de estudo}

As amostragens de drosofilídeos foram realizadas em três áreas dentro do domínio da Floresta Atlântica no Centro de Endemismo de Pernambuco. Foram investigadas uma área de plantação de eucaliptos, uma plantação de bambus e um fragmento de Floresta Atlântica, todos com tamanho aproximado de 60 hectares, pertencentes à empresa de transformação de papel Ondunorte, localizada no município de Moreno, Pernambuco, na propriedade "Fazenda Veneza” (8 5' 58” S, 10’ 48” 0).

\section{Coleta de drosofilídeos}

Drosofilídeos adultos foram capturados com armadilhas confeccionadas com garrafas pet, contendo isca de banana, de acordo com o modelo descrito por Tidon e Sene (1988). Em cada coleta foram utilizadas 10 armadilhas, as quais foram distribuídas ao longo da área de estudo aleatoriamente e distanciadas pelo menos 30 metros uma da outra. As armadilhas foram penduradas em árvores a uma altura de 1,5 metros do solo e deixadas por um período de três dias consecutivos para atração dos insetos.Foram realizadas seis amostragens em cada área de estudo, sendo três no período de maior pluviosidade (entre julho e agosto de 2015) e três no período de maior estiagem (entre outubro de 2015 e janeiro de 2016). Os drosofilídeos coletados foram identificados através da morfologia externa.

\section{Análise dos dados}

Para a análise dos dados as espécies foram reunidas em dois grupos: 1) Nativas da região Neotropical e 2) Exóticas. O teste de qui quadrado $\left(X^{2}\right)$ foi utilizado para avaliar diferenças significativas na abundância nestes dois grupos de espécies entre os ambientes e entre as estações. 


\section{RESULTADOS E DISCUSSÃO}

Foram coletados 28.666 indivíduos da família Drosophilidae nos ambientes investigados, deste total 49,35\% foram observados na área de Floresta nativa, 28,75\% na plantação de eucaliptos e 21,90\% na plantação de bambus.

$\mathrm{Na}$ Floresta nativa e na plantação de bambus as espécies nativas foram significativamente mais abundantes em relação às exóticas $\left(X^{2}=27,243\right.$; grau de liberdade $=1$, $\mathrm{P}<0,0001$ e $X^{2}=1331$; grau de liberdade $\left.=1, \mathrm{P}<0,0001\right)$. Já na plantação de eucaliptos as exóticas foram significativamente mais abundantes $\left(X^{2}=872,029\right.$; grau de liberdade $=1$, $\mathrm{P}<0,0001)$. A abundância absoluta das espécies nativas e exóticas em cada área estudada está ilustrada na Figura 1.

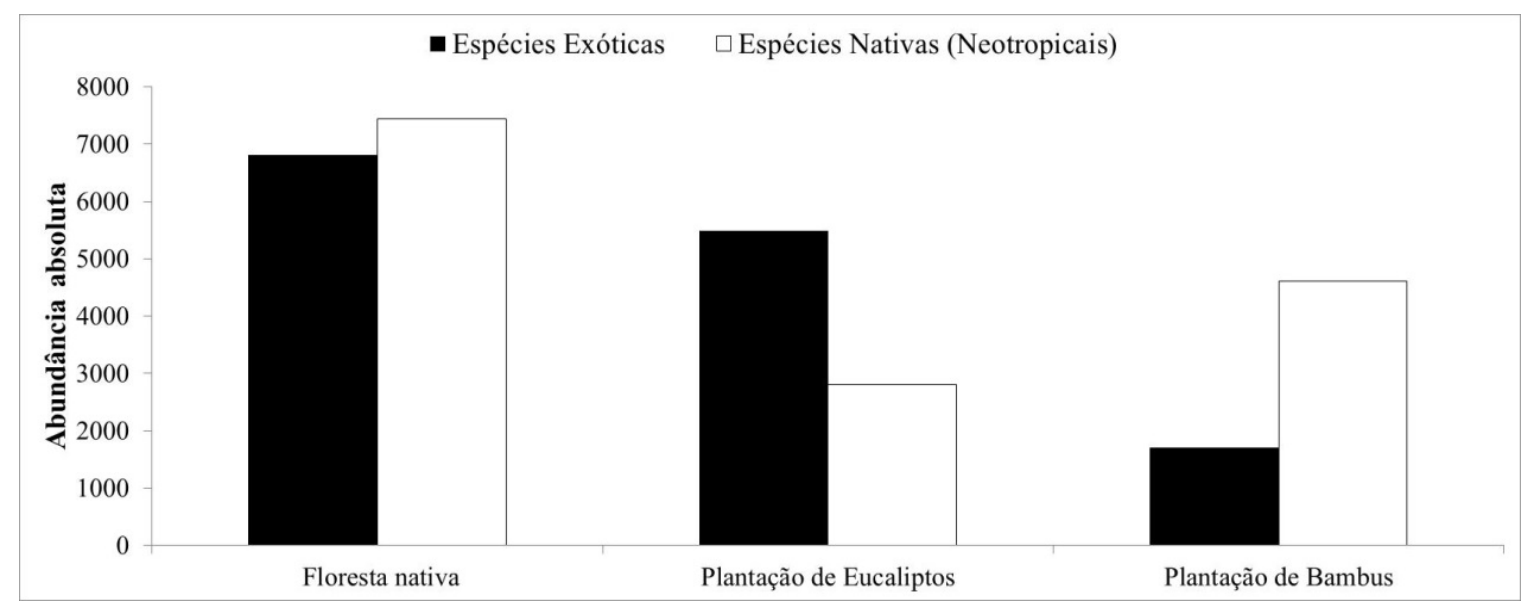

Figura 1. Abundância absoluta de espécies exóticas e nativas (Neotropicais) de drosofilídeos em uma área de Floresta Atlântica nativa, uma plantação de eucaliptos e uma plantação de bambus no domínio da Floresta Atlântica no Centro de Endemismo de Pernambuco.

Em um estudo realizado no domínio do Cerrado Brasileiro Emerich (2011) comparou a abundância de drosofilídeos em áreas de vegetação nativa e áreas de monocultura de soja, observando maior abundância de espécies exóticas nas plantações. O autor salienta, em concordância com outros estudos (Penariol; Madi-Ravazzi, 2013), que as espécies exóticas de drosofilídeos estão mais associadas a ambientes secos e quentes. No nosso estudo o ambiente mais seco e quente é a plantação de eucaliptos, o que pode justificar a maior abundância de espécies exóticas neste local.

Neste trabalho verificamos que as espécies nativas de drosofilídeosforam significativamente mais abundantes na estação chuvosa $\left(X^{2}=836,807\right.$; graus de liberdade $=2$, $\mathrm{P}<0,0001)$ e as exóticas na estação seca $\left(X^{2}=1121,966\right.$; graus de liberdade $\left.=2, \mathrm{P}<0,0001\right)$. Na Tabela 1 estão descritas as abundâncias absolutas destes dois grupos de espécies por estação (seca e chuvosa) nos três ambientes estudados. 
Tabela 1. Abundância absoluta de drosofilídeos nativos da região Neotropical e exóticos por estação (chuvosa e seca) em uma área de Floreta Atlântica nativa, uma plantação de eucaliptos e uma plantação de bambus no domínio da Floresta Atlântica no Centro de Endemismo de Pernambuco.

\begin{tabular}{lcccc}
\hline \multirow{2}{*}{ Ambiente } & \multicolumn{2}{c}{ Estação chuvosa } & \multicolumn{2}{c}{ Estação seca } \\
\cline { 2 - 5 } & Nativa & Exótica & Nativa & Exótica \\
\hline Floresta & 6208 & 229 & 1227 & 6583 \\
Eucalipto & 2321 & 641 & 483 & 4853 \\
Bambu & 3674 & 305 & 937 & 1405 \\
\hline
\end{tabular}

A maior abundância de espécies exóticas na estação seca e das nativas na estação chuvosa também foi observada no Cerrado brasileiro (EMERICH, 2011).Esses dados evidenciam que espécies exóticas de drosofilídeos estão mais adaptadas à estação seca e as nativas à estação mais úmida. A retração do tamanho populacional das espécies Neotropicais no período de maior estiagem também poderia ser explicada pela possível menor disponibilidade de alimentos nesta estação, assim como já documentado para o Cerrado (SANO e ALMEIDA, 1998). Esta situação poderia ser mais bem suportada pelas exóticas pelo fato deste grupo incluir um maior número de espécies generalistas (ROQUE et al., 2009).

\section{CONCLUSÕES}

Neste trabalho observamos que na Floresta nativa e na plantação de bambus as espécies nativas de drosofilídeos foram significativamente mais abundantes em relação às exóticas.A maior abundância de espécies exóticas foi observada na plantação de eucaliptos, provavelmente por serem locais mais abertos e mais quentes em comparação com os outros dois ambientes investigados, favorecendo a presença de espécies exóticas nestes. Este resultado revela um padrão heterogêneo na abundância de espécies nativas e exóticas de drosofilídeos entre diferentes tipos de plantações.

As espécies nativas de drosofilídeos foram significativamente mais abundantes na estação chuvosa e às espécies exóticas na estação seca, demonstrando, mais uma vez a preferência das espécies exóticas por ambientes mais secos.

Nota-se que os drosofilídeos são excelentes organismos para estudar padrões de abundância em diferentes ambientes e entre as estações do ano, uma vez que estes organismos apresentaram diferenças significativas na abundância em relação às variações sazonais e as áreas estudadas.

\section{REFERÊNCIAS}

CUNHA, A. A.; GUEDES F. B. Mapeamentos para conservação e recuperação da biodiversidade na Mata Atlântica: em busca de uma estratégia espacial integradora para orientar ações aplicadas. Brasília: Ministério do Meio Ambiente, Secretaria de Biodiversidade e Florestas, 2013.

EMERICH, P. P. Efeitos de matrizes ambientais sobre assembleias de drosofilídeos (Insecta, Diptera) de mata de galeria. Brasília: Instituto de Ciências Biológicas, Universidade de Brasília, 2011. (Dissertação de Mestrado).

LINDENMAYER, D. B.; FRANKLIN, J. F. Conserving forest biodiversity: a comprehensive multiscaled approach. Washington: Island Press, 2002.

PENARIOL, L. V.; MADI-RAVAZZI, L. Edge-interior diferences in the species richness and abundance of drosophilids in a semideciduos forest fragment. Springer plus, p. 1-7, 2013. 
POWELL, J.R. Progress and prospects in evolutionary biology: The Drosophila Model. Oxford: Oxford University Press, 1997.

RODRIGUES, A. S. L.; ANDELMAN, S. J.; BAKARR, M. I.; BOITANI, L.; BROOKS, T. M.; COWLING, R. M.; FISHPOOL, L. D. C.; FONSECA, G. A. B.; GASTON, K. J.; HOFFMANN, M.; LONG, J. S.; MARQUET, P. A.; PILGRIM, J. D.; PRESSEY, R. L.; SCHIPPER, J.; SECHREST, W.; STUART, S. N.; UNDERHILL, L. G.; WALLER, R. W.; WATTS, M. E. J.; YAN, X. Effectiveness of the global protected area network in representing species diversity. Nature, v. 428, p.640-643, 2004. http://dx.doi.org/10.1038/nature02422

ROQUE, F.; HAY, J. D. V.; TIDON, R. Breeding sites of drosophilids (Diptera) in the Brazilian Savanna. I. Fallen fruits of Emmotum nitens (Icacinaceae), Hancornia speciosa (Apocynaceae) and Anacardium humile (Anacardiaceae). Rev. Bras. Entomol, v. 53, p. 308-313, 2009.

SANO, S.M.; ALMEIDA, S.P. Cerrado: ambiente e flora. Planaltina: Embrapa-CPAC, 1998.

SUKOPP, H., WERNER, P. Nature in cities: a report and view of studies and experiments concerning ecology, wildlife and nature conservation in urban and suburban areas. Strasbourg: Council of Europe, European Committee for the Conservation of Nature and Natural Resources, 1982.

TIDON, R.; SENE, F. M. A trap that retains and keeps Drosophila alive. Drosophila Information Service, n. 67, p. 89, 1988. 